\title{
PROCESS IMPROVEMENT FOR THE PRODUCTION OF GRAB BARS WITH LEAN APPROACH
}

\author{
DOI: 10.17261/Pressacademia.2018.898 \\ PAP- V.7-2018(51)-p.281-284
}

Hatice Esra Yener ${ }^{1}$, Ezgi Kececioglu², Mustafa Batuhan Ayhan ${ }^{3}$

${ }^{1}$ Marmara University, M.U. Goztepe Campus 34722 Kadıkoy, Istanbul, Turkey. esra1995@hotmail.com, ORCID:0000-0002-2398-5637

${ }^{2}$ Marmara University, M.U. Goztepe Campus 34722 Kadıkoy, Istanbul, Turkey. ezgi.kececioglu9@hotmail.com, ORCID: 0000-0003-3616-0578

${ }^{3}$ Marmara University, M.U. Goztepe Campus 34722 Kadıkoy, Istanbul, Turkey.

batuhan.ayhan@marmara.edu.tr, ORCID: 0000-0001-6114-7629

To cite this document

Yener, H. E., Kececioglu, E., Ayhan, M. B. (2018). Process improvement for the production of grab bars with lean approach. PressAcademia Procedia (PAP), V.7, p.281-284

Permemant link to this document: $h$ ttp://doi.org/10.17261/Pressacademia.2018.898

Copyright: Published by PressAcademia and limited licenced re-use rights only.

\section{ABSTRACT}

Purpose- This project aims to analyze and improve the production processes of grab bars which is one of the bill materials of buses that are manufactured in one of the leading automotive companies.

Methodology- Value Stream Mapping is used to understand production processes of grab bars for the existing state. Based on this analysis, important parameters such as cycle times, process times are recorded. Then by the help of lean approach, points that can be improved are determined. Due to the these suggestions, a new production process is proposed. To check the validity of the proposed production process, it is run with ARENA Software. As last, Value Stream Mapping is re-designed to display the improvements on the parameters.

Findings- Many parameters of production process of current state are improved by applying the lean approaches and validated via ARENA simulation. According to future state ARENA model, the number of completed bars has increased by $24 \%$ and the number of defected bars has decreased by $\% 50$.

Conclusion- The main contribution of this study is in two-folds. Firstly, the production process of grab bars is analyzed in detail and represented by Value Stream Mapping. Secondly, Lean Approach is employed to improve the existing grab production processes.

Keywords: Lean manufacturing, value stream mapping, arena software, simulation, grab bars production. JEL Codes: C63, L62, M11

\section{INTRODUCTION}

Grab bars as shown in Figure 1, are used in buses to provide security and comfortability of passengers during their journey. The project aims to improve the production processes of grab bars. Decreasing lead times, minimizing the amount of defects in grab bars are targeted. Increasing the total quality is also on the focal point of this study.

Figure 1: An Example of Grab Bars in a Bus

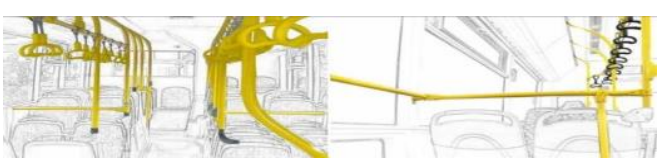

As shown in Figure 2, initially, metal bars composed of steel are supplied from a local vendor. The production processes of grab bars begin with cutting bars operation. For each bus, a documentation consisting of technical requirements of related bus is prepared. Also, each bar has a unique part number. Grab bars are cut in lots in the light of this documentation. After cutting process, bars are separated according to part numbers and placed in vehicles specifically designed for transferring these parts. In bending \& welding station, bars are bended regarding with their part numbers in lots. Then, bars to be welded and not to be welded are placed in different transfer vehicles. Before the welding process, bars are collected as a set according to their part numbers. These bars are passed through welding, grinding and pneumatic sanding processes, respectively. After the aforementioned processes, all bars are transferred to the phosphate atelier. In phosphating stage, bars are surfaced with phosphate. Then, bars are transferred with pallets to the painting station. Phosphating bars are painted in different colours according to customers' preferences in painting with powder paint operation. The painted bars are cured in order to dry. Then, bars are packaged and placed in pallets again one by one. After completion of four production processes, bars are transported to warehouse and bars wait for two hours in assembly warehouse. Some of the grab bars have preliminary preparation processes. In related station, these bars are passed through a variety of operations such as surfacing bars protective equipment, extension 
of hole etc. Others are grouped in a set and placed in transfer vehicles. Final stage is the assembly process. Assembling of grab bars on buses is performed in this process and finally grab bars' production processes get completed.

\section{Figure 2: Production Processes of Grab Bars}

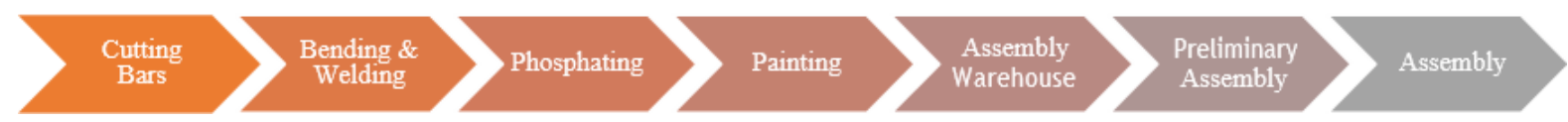

\section{LITERATURE REVIEW}

Literature review is performed in order to gather comprehensive information about lean production and its methodologies. Under the favour of literature review, the methodologies of this study, constituting value stream mapping and evaluating current state by using Arena Software in order to improve production processes of grab bars, are determined. Therefore, it is very crucial to determine in advance the alternatives that will contribute to the process and to give an idea if the study has reached its goal.

Karim and Arif-Uz-Zaman (2013) pointed in their research implementing appropriate lean strategies is crucial for firms in order to obtain high quality products with lower cost and eliminate waste from their manufacturing activities. Incorrect application of lean strategies causes undesired results for firms. These results can be listed as: Consuming excessive time and resources, second class products, lack of confidence for employees so on so forth. Although there are several sources about lean manufacturing and lean tools, there is lack of sources about implementing an appropriate lean tools in manufacturing areas.

Kiliç and Ayvaz (2016) deal with practicability of lean production and defining the concept of waste. They state the importance of implementation of lean manufacturing and evaluate it throughout the history. In the light of authors' examination, lean implementation is more common concept for automotive industry than it is in other industries. Another consequence of this examination is that all lean tools cannot be implemented simultaneously, only one or some of them can be used with together. Researchers practice their studies at Royal Conta Sanayi ve Ticaret A.Ş. which is a sub-industry of automotive sector produces seals. Throughout the study, lean tools such as 5 , SMED, Kaizen, Poka-Yoke were used. Consequently, listed results were obtained: Production area of utilization was decreased with the proportion of $35 \%$, lead time of seals reduced from 53 days to 10 days, integration of lean tools was proved and lastly production capacity increased by 1.5 times.

Birgün S. et al. (2006) states in their research paper that one of the tools of lean production approach which is value stream mapping definitely improves manufacturing process of UZEL A.Ş. This company is a large-scale company in the field of tractor production. They proved their claim in real implementation of producing hydraulic gates that is one of the bill of material of tractors. Proposed methodology can be listed as follows: selection of product family, defining system and value flow of hydraulic gates, analysing current situation and based of related observation and examination, designing future case. Their research proposes the crucial solution suggestions for the benefit of both company and literature in producing hydraulic gate processes by using value stream mapping.

Gupta and Jain (2013) stated that in order to understand lean manufacturing, it is a must to realise the meaning of a 'waste' which is the main concept of lean. Waste can be described as anything that does not add-value for the product and in the origin of lean concept. There are 7 types of wastes: Transportation, Inventory, Motion, Waiting, Over-processing, Overproduction and Defects. Lean manufacturing aims to reduce/eliminate these type of wastes that customers do not want to pay by using lean tools and methods such as Kaizen, $5 \mathrm{~S}$, VSM (Value Stream Mapping), Kanban, MRP (Material Requirement Planning) etc. These methods help to reduce lead time, improve quality and efficiency that are keys to companies' successes. Moreover, lean manufacturing is a kind of revolution. The culture of company and employee attitudes also must be adopted by its methodology.

\section{DATA AND METHODOLOGY}

In this study, data collection methods are basically time studies and historical data provided by the company without violating confidentiality policies. Time studies are carried out 36 times in order to determine cycle times of each processes of bar production. Also, from Quality Assurance department, the rate of defective bars occurred last two years are taken. According to these historical data, defective bars existed in mainly preliminary assembly operations with the proportion of $55 \%$ and assembly operations with the proportion of $30 \%$. Hence, these operations became focal points of this study.

After the selection of production group and determining objectives, the current state value stream mapping is constituted. This map includes all events both value added and non-value added activities in production of a bar from beginning to end.

Figure 3 illustrates current state value stream mapping of related processes. Under processes, there are information boxes that showscycle times in minutes, number of shifts and number of machines and yellow boxes show number of workers. Also inventory of 240 bars is shown with inventory icon. Regarding with these data, value added time and non-value added time are calculated. 
Figure 3: Current State Value Stream Mapping

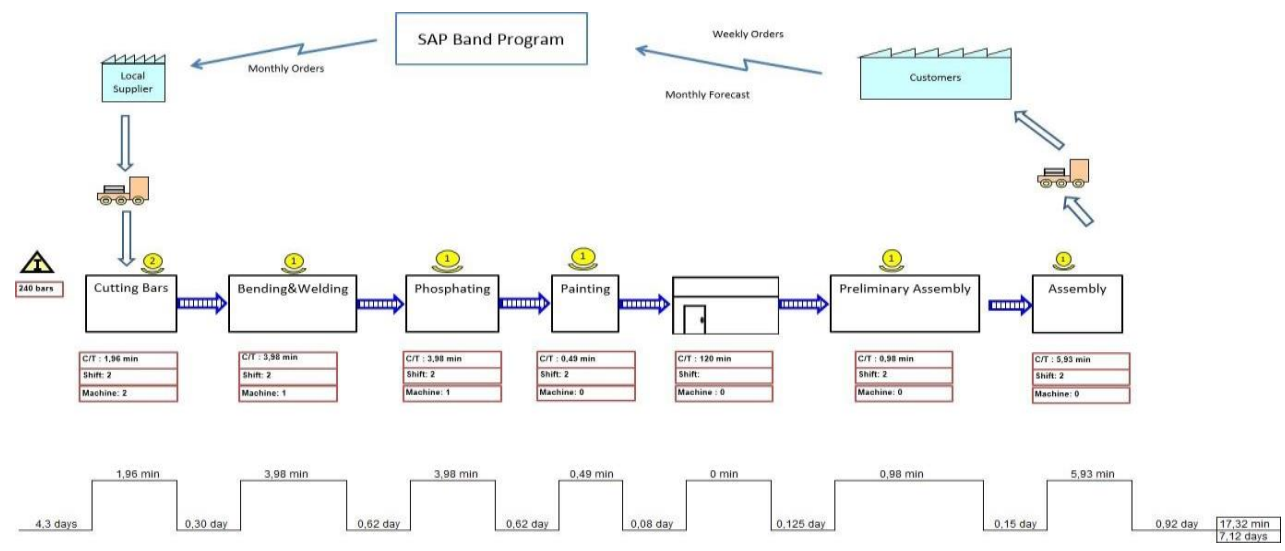

From current state value stream mapping and results of current state ARENA the relation between value-added activities and non-value added activities is determined. In order to obtain improved processes solution suggestions are proposed and implemented on Future State Value Stream Mapping.

\section{FINDINGS}

In order to improve the production processes of grab bars, solution suggestions are proposed and listed below:

\subsection{Placing drilling operations that are done in preliminary assembly section into body shop between phosphating station and painting station.}

In the current situation, drilling operation on bars is carried out in preliminary assembly station. Workers drill a hole on bars manually and this operation takes approximately 44 seconds per bar. Manual operation causes defects on bars. In order to recover damaged bars, repainting operation may be needed. If the hole drilling operation is taken after the phosphating process, recoverable damages which occur during the hole drilling could be corrected with painting. Also holes on bars could be drilled with the help of computer aided laser technology instead of manual operation since drilling operation with laser takes only 5 seconds per bar. This way, the risk of getting damaged of bars could be reduced and there is no need for re- painting operation in grab bars production processes. At the same time, time saving is also provided.

At the plant, drilling operation with laser technology is already carried out in production processes of different parts of busses. For this solution suggestion, additional time studies are performed in the stations that already use laser technology in order to predict the cycle time of drilling operation with laser technology. The cycle time of drilling operation with laser is expected to be 5 seconds per bar.

\subsection{Rearranging the preliminary assembly workbench:}

In preliminary assembly atelier, many processes such as drilling, expansion of the hole are carried out on preliminary assembly workbench. During these processes, burrs are formed and accumulated on this workbench. Painted bars are scratched and damaged because of these burrs on the workbench while preliminary assembly processes are occurred and this situation causes re-painting of the scratched bars. A potential solution suggestion for this situation is to rearrange the workbench with an adjustable apparatus as shown in Figure 4 in order to prevent the contact the surface of bars with burrs. Thus, excessive labours arising from re-painting operation will be eliminated. Also, it is foreseen that the rate of non-conforming bars is decreased by $3 \%$ in the quality control mechanism after preliminary assembly operations. This adjustable equipment may be produced in the part-production atelier, therefore this solution suggestion offers a cost-effective way.

\section{Figure 4: An Example of Apparatus to be equipped on Preliminary Assembly Workbench}

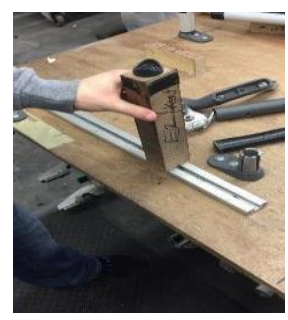




\subsection{Displacement of luggage rack and its bars assembly process from assembly line to preliminary assembly atelier}

Luggage rack is also one of the bill of materials of buses and luggage rack assembly is related with the assembly process of grab bars because some bars are assembled on this luggage rack. At the current state, luggage rack and bars are assembled in assembly line. However, it is observed that bars are considerably getting damaged because of limited movement area and insufficient lighting in buses during assembly process. While luggage rack and its bars are assembled, they may hit another parts of buses and some damages occur due to the poor conditions. Because of these poor conditions, there is also an occupational accident risk for employees. In addition to this, inside of bus became dirty.

Repairing bars or reproducing them are excessive labours, cleaning of bus interior is also non-value adding activity for this production process. Possible solution suggestion for this situation is to perform this assembly process at preliminary assembly atelier, which means at outside of the buses. It is forecasted that preliminary atelier conditions offer more comfortable and lighter than assembly line conditions. Through these better conditions, eliminating aforementioned excessive labours and removing the possibility of occupational accident risk are expected.

In future state value stream mapping, there is no difference on cutting bars, bending \& welding and phosphating operations. A new process named "drilling operation with laser" is added between phosphating operation and painting operation. In the current situation drilling on bars is performed in preliminary assembly station manually and cycle time of drilling operation is composed of $75 \%$ of preliminary assembly operation. Laser technology is an enhanced technology and it makes drilling process much more easier, fast and defect free within 4,8 seconds per bar. This way, the cycle time of drilling on bars is reduced by $89 \%$. The potential risk of bars to be damaged is also avoided.

\section{CONCLUSION}

Within the scope of this project, improvement activities on production processes of grab bars are carried out. Literature review about lean manufacturing, tools and its implementation were performed. In the light of all studies reviewed, the methodology which is constituting current state value stream mapping and future state value stream mapping were defined. Also it is observed that Value Stream Mapping is used for solving similar problems in several studies in the literature. After that, data collection phase of this study was completed. Time studies were performed many times in related production area and also historical data was provided by company.

At the end of data analyses, the current state value stream mapping was created with cycle time values, inventory information and number of machine, operators, and shifts. Current State Value Stream Mapping is a useful methodology to understand the association between value added activities and non- value added activities but this methodology seems to be insufficient to have certain ideas about related production processes. Therefore, simulation was selected as another methodology for this study with Current State Value Stream Mapping.

In order to achieve desired results and remove problems of grab bars production processes, solution suggestions were proposed. In the light of these suggestions, in Future State Value Stream Mapping and ARENA models, initial processes consisting of cutting, bending \& welding, phosphating and painting processes remain the same. Due to the higher failure rate and quality issues, preliminary assembly and assembly stations are re-organized.

According to the current state ARENA report, while grab bars production for 139 buses are completed, grab bars for 10 buses are rejected. On the other hand, in improved model, 172 buses' grab bars are finalised whereas 5 buses' grab bars are defective. Therefore, with the future model, the number of completed bars is increased by $24 \%$ and the number of defected bars is decreased by $\% 50$. In other words, it is expected to improve the production processes of grab bars by implementing proposed model. Since there is no considerable changes between current \& future utilizations on ARENA models, proposed solution suggestions have no negative impact on the workers' utilization.

\section{REFERENCES}

Birgün, S., Gülen, K. G., Özkan, K. (2006). Yalın üretime geçiş sürecinde değer akışı haritalama tekniğinin kullanilmasi: imalat sektöründe bir uygulama. İstanbul Ticaret Üniversitesi Fen Bilimleri Dergisi, 5(9), 47-59.

Gupta, S., Jain, S. K. (2013). A literature review of lean manufacturing. International Journal of Management Science and Engineering Management, 8(4), 241-249.

Karim, A., Arif-Uz-Zaman, K. (2013). A methodology for effective implementation of lean strategies and its performance evaluation in manufacturing organizations. Business Process Management Journal, 19(1), 169-196.

Kılıç, A., Ayvaz, B. (2016). Türkiye otomotiv yan sanayinde yalın üretim uygulaması. İstanbul Ticaret Üniversitesi Fen Bilimleri Dergisi, 15(29), $29-60$. 